\title{
Validation of respirometry as a short-term method to assess the efficacy of biocides
}

\author{
M. SIMÕES, M. O. PEREIRA \& M. J. VIEIRA \\ Centro de Engenharia Biológica, Universidade do Minho, Braga, Portugal
}

(Received 12 October 2004; accepted 28 fanuary 2005)

\begin{abstract}
This study shows that a short-term respirometric measurement based on the rate of oxygen uptake needed to oxidize glucose is a reliable and fast method to assess biocide efficacy against P. fluorescens cells. Respiratory activity using oxygen consumption rate, the determination of viable and nonviable cells using Live/Dead ${ }^{\mathbb{B}}$ BacLight ${ }^{\mathrm{TM}}$ kit and colony formation units (CFU), were compared as indicators of the biocidal efficacy of ortho-phthalaldehyde (OPA). The results showed that determining the effect of OPA against $P$. fluorescens using the different methods leads to different conclusions. The minimum bactericidal concentration (MBC) was $80 \mathrm{mg} \mathrm{l}^{-1}, 100 \mathrm{mg} \mathrm{l}^{-1}$ and $65 \mathrm{mg} \mathrm{l}^{-1}$ respectively, using respiratory activity, viability using BacLight counts and culturability. The plate count method was shown to underestimate the biocidal action of OPA, whilst data from respirometry and viability using Live/Dead BacLight kit correlated strongly and were not statistically different when yellow cells were considered nonviable. Respirometry therefore represents an expeditious, non-destructive and accurate method to determine the antimicrobial action of biocides against aerobic heterotrophic bacteria.
\end{abstract}

Keywords: Respiratory activity, Live/Dead BacLight ${ }^{T M}$, culturability, viability, disinfection, biocide

\section{Introduction}

The disinfection efficacy of chemical biocides and the subsequent assessment of the microbiological metabolic state of the microorganisms can be evaluated by a variety of methodological approaches. The assessment of the efficacy of a biocide is very important since misleading results may give rise to inefficient disinfection protocols. Traditionally, for heterotrophic bacteria biocide efficacy has been evaluated by colony count enumeration (Stewart et al. 1994). However, bacteria recovered on the solid media only represent culturable bacteria that are able to initiate cell division on that medium (Boulos et al. 1999) whilst viable bacteria without the ability to grow on solid media are not accounted for. In addition, the culture method cannot be used accurately to evaluate the effect of biocides on biofilms. Consequently, several other methods have been proposed as alternatives to the plate count method such as bioluminescence, impedimetry and respiratory activity (Stewart et al. 1994). Respiratory activity can be determined by assessing the reduction of the redox stains CTC (5-cyano-2, 3-ditolyl tetrazolium chloride), INT (2-(4-iodophenyl)-3-(4- nitrophenyl)-5-phenyl tetrazolium chloride) (Smith \& McFeters, 1997; Hatzinger et al. 2003) and XTT (benzenesulfonic acid hydrate) (Hatzinger et al. 2003), followed by observation of the cells using direct microscopy and evaluation of the glucose consumption rate (Simões et al. 2003b). Other methods such as the application of a specific or a combination of fluorochromes, with the use of direct microscopy (Terzieva et al. 1996; Boulos et al. 1999) and flow cytometry (Terzieva et al. 1996; Virta et al. 1998) have also been proposed to enumerate viable bacteria. More recently, molecular marker systems and detection methods have been applied to identify and quantify specific microorganisms as well as to provide an indication of their viability (Yoshinori et al. 2002).

Respiratory activity measured by oxygen uptake rate due to glucose oxidation has already been used to assess the potential of antimicrobial agents against planktonic bacteria and biofilms (Pereira \& Vieira, 2001; Simões et al. 2003a; 2003b; 2003c; 2005). However, no reports are available concerning the advantages and drawbacks of this technique. The present study was designed to measure respiratory activity in order to assess biocidal

Correspondence: Maria João Vieira, Centro de Engenharia Biológica-IBQF, Universidade do Minho, $4710-057$ Braga, Portugal. Fax: 00351253678986.

E-mail:mjv@deb.uminho.pt

ISSN 0892-7014 print/ISSN 1029-2454 online (C) 2005 Taylor \& Francis Group Ltd

DOI: $10.1080 / 08927010500066982$ 
efficacy against $P$. fluorescens cells. The respiratory activity method using oxygen consumption rate due to glucose oxidation, the determination of viable and nonviable cells using Live/Dead ${ }^{\mathbb{B}}$ BacLight $^{\mathrm{TM}}$ kit and colony formation units on Plate Count Agar were used as indicators of the microbiocidal efficacy of ortho-phthalaldehyde.

\section{Material and methods}

\section{Microorganism and cell growth}

Pseudomonas fluorescens (ATCC $13525^{\mathrm{T}}$ ) was used as the test organism; the optimal growth conditions are $27^{\circ} \mathrm{C}, \mathrm{pH} 7$ with glucose as the carbon source (Oliveira et al. 1994). A continuous culture of $P$. fluorescens was grown at $27^{\circ} \mathrm{C}$ in a 21 glass reactor, aerated and magnetically agitated. The reactor was continuously fed with $10 \mathrm{ml} \mathrm{h}^{-1}$ of a sterile nutrient solution composed of $5 \mathrm{~g} \mathrm{l}^{-1}$ glucose, $2.5 \mathrm{~g} \mathrm{l}^{-1}$ peptone and $1.25 \mathrm{~g} \mathrm{l}^{-1}$ yeast extract, in phosphate buffer $(0.01 \mathrm{M}) \mathrm{pH} 7$.

\section{Biocide}

The biocide used was ortho-phthalaldehyde (OPA) obtained as a powder from Sigma (P-1378). Before each experiment, biocide solutions were prepared to the required concentration, with sterile distilled water.

\section{Biocide application}

A $P$. fluorescens suspension culture was sampled from the reactor, centrifuged $(3777 g, 5 \mathrm{~min})$ and washed three times with saline $(\mathrm{NaCl} 0.85 \%)$ phosphate buffer $\mathrm{pH}$ 7. The pellets were resuspended in phosphate buffer $(0.01 \mathrm{M}) \mathrm{pH} 7$ in order to obtain a final bacterial suspension with an optical density of $0.4(\lambda=640 \mathrm{~nm})$. This bacterial culture was divided between several sterilized glass flasks that were placed in an orbital shaker $(120 \mathrm{rpm})$. The cell suspensions were exposed to a range of biocide concentrations $(2,7,10,15,20,25,30,35,40,45$, $55,65,80$ and $\left.100 \mathrm{mg}^{-1}\right)$ for $30 \mathrm{~min}$. After the required contact time, the biocide was neutralized as described below. From each bacterial suspension, several volumes were sampled in order to assess the metabolic state of the bacteria by respiratory activity, bacterial staining after microfiltration and agar plate cultivation. Three replicate experiments, each with triplicate samples, were performed for each condition tested, and for each method used.

\section{Biocide neutralization}

Sodium bisulphite (Aldrich), at a final concentration of $0.5 \%(\mathrm{w} / \mathrm{v})$ was added for $10 \mathrm{~min}$ (Walsh et al.
1999) to the bacterial cultures immediately after the 30 min biocide contact time.

\section{Assessment of bacterial respiratory activity}

The respiratory activity of the bacterial samples was evaluated by measuring the rate of oxygen uptake in a biological oxygen monitor (BOM) during shortterm assays. The assays were performed in a Yellow Springs Instruments (YSI Co. Inc., Ohio) BOM (Model 53) according to the procedure described by Simões et al. (2003b). Briefly, for each respirometric assay, samples of each bacterial suspension were placed in the temperature-controlled vessel of the BOM, after being in contact with the biocide and neutralizer. The temperature in the measuring chamber was $27^{\circ} \mathrm{C}$. The vessels contained dissolved oxygen (DO) probes connected to a DO meter. Once inside the vessels, the bacterial cultures were aerated for $30 \mathrm{~min}$ to ensure oxygen saturation. After reaching $\mathrm{O}_{2}$ saturation, the vessels were closed and the decrease in oxygen concentration was monitored over time. The linear decrease observed between time zero and glucose addition corresponds to the endogenous respiration rate. To determine the oxygen uptake rate due to substrate oxidation, a small volume $(50 \mu \mathrm{l})$ of a glucose solution (100 $\mathrm{mg} \mathrm{l}^{-1}$ ) was injected into each vessel. The slope of the linear decrease in the DO concentration immediately after glucose injection corresponds to the total respiration rate. The difference between the two respiration rates (total and endogenous) gives the concentration of $\mathrm{O}_{2}$ used by the bacteria for the oxidation of the glucose - exogenous respiration rate.

The respiratory activity (endogeneous or exogeneous) was expressed in $\mathrm{mg}$ of oxygen $\mathrm{g}^{-1}$ dry bacterial mass $\min ^{-1}$. The dry bacterial mass was assessed by the determination of the total volatile solids in the bacterial suspension, according to the Standard Methods (APHA, AWWA, WPCF, 1989), method number 2540 A-D.

\section{Assessment of viability by staining}

The viability of $P$. fluorescens was assessed with L-7012 Live/Dead $^{\circledR}$ (L/D) BacLight ${ }^{\text {TM }}$ Bacterial Viability kit developed by Molecular Probes Inc., using epifluorescence microscopy. This fast epifluorescence staining method was applied to estimate both viable and total counts of bacteria. BacLight is composed of two nucleic acid-binding stains: SYTO $9^{\mathrm{TM}}$ and propidium iodide (PI). SYTO $9^{\mathrm{TM}}$ penetrates all bacterial membranes and stains the cells green, while propidium iodide only penetrates cells with damaged membranes, and the combination of the two stains produces red fluorescing cells. 
After biocide treatment and neutralization, the various bacterial suspensions were diluted $1: 10$ and $300 \mu \mathrm{l}$ of each diluted suspension were filtered

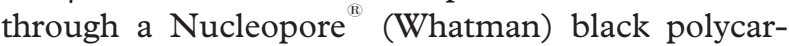
bonate membrane (pore size $0.22 \mu \mathrm{m}$ ) and stained with $250 \mu$ l diluted component A (SYTO 9) and $250 \mu$ l diluted component $\mathrm{B}$ (propidium iodide) for $15 \mathrm{~min}$ in the dark at $27 \pm 1^{\circ} \mathrm{C}$. The membrane was mounted in BacLight mounting oil as described in the instructions provided by the manufacturer.

Dye solutions were prepared by dissolving $3 \mu \mathrm{l}$ of component A in $1 \mathrm{ml}$ of sterile-filtered (pore size $0.22 \mu \mathrm{m}$ ) distilled water and the same procedure was followed for component B. To observe the stained bacteria, a Zeiss (Axioskop) microscope fitted with fluorescence illumination was used with a $100 \times$ oil immersion fluorescence objective. The optical filter combination for optimal viewing of stained preparations consisted of a 480 to $500 \mathrm{~nm}$ excitation filter in combination with a $485 \mathrm{~nm}$ emission filter. The micrographs were obtained using a microscope camera (AxioCam HRC, Carl Zeiss). A program path (AxioVision, Carl Zeiss Vision) involving image acquisition and image processing was used to obtain the images. A program path (Sigma Scan Pro 5, Sigma) involving object measurement and data output was used to obtain the number of viable and nonviable cells. The number of viable and nonviable bacteria on each membrane was estimated from counts of a minimum of 20 fields of view. The range of total cells for each field was between $50-$ 200 cells/field.

\section{Culturability method on Plate Count Agar}

The selection of an adequate medium for heterotrophic microbial growth is an important factor in the use of plate count method. In this work, tests were carried out in order to determine the appropriate medium. Plate Count Agar (PCA; Merck) was chosen since it allowed small colonies to grow, preventing larger colonies from excessive growth through limiting diffusion of medium components. After biocide neutralization, the bacterial samples were diluted to the adequate cellular concentration in phosphate buffer. A volume of $30 \mu \mathrm{l}$ of the bacterial diluted suspension were transferred onto PCA plates. Colony enumeration was carried out after $48 \mathrm{~h}$ at $27^{\circ} \mathrm{C}$.

\section{Calculations and statistical analysis}

The loss of activity, viability and culturability due to biocide treatment, obtained by the different methods were calculated using the follow equations:
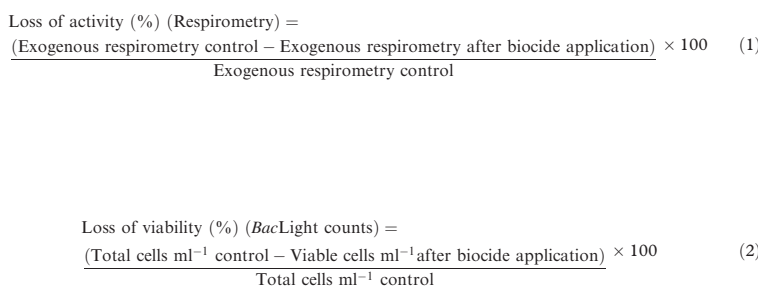

Loss of culturability $(\%)($ Plate count $)=$

$\left(\mathrm{CFU} \mathrm{ml}{ }^{-1}\right.$ control $-\mathrm{CFU} \mathrm{m}^{-1}$ after biocide application) $\times 100$

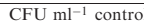

Log reduction $=\mathrm{Log}\left(\right.$ number of cells or $\mathrm{CFU} \mathrm{ml}{ }^{-1}$ control) $-\mathrm{Log}$ (number of cells or $\mathrm{CFU} \mathrm{ml}{ }^{-1}$ after biocide application)

The MBC (minimum bactericidal concentration) for each method was determined as the lowest concentration of biocide where no activity, viability or culturability was detected according to Johnson et al. (2002). Paired $t$-test analyses were performed to estimate whether or not there was a significant difference between the results obtained by the different methods. Statistical calculations were based on confidence level equal or higher than $95 \%$.

\section{Results}

The influence of OPA concentration on the activity, viability and culturability of $P$. fluorescens cells was evaluated through three different methods, viz. respiratory activity, BacLight viability staining, and colony formation on Plate Count Agar (culturability). Figures 1, 4 and 5 present, respectively, the values of the respiratory activity (exogenous and endogenous) per gram of cells, the number of viable

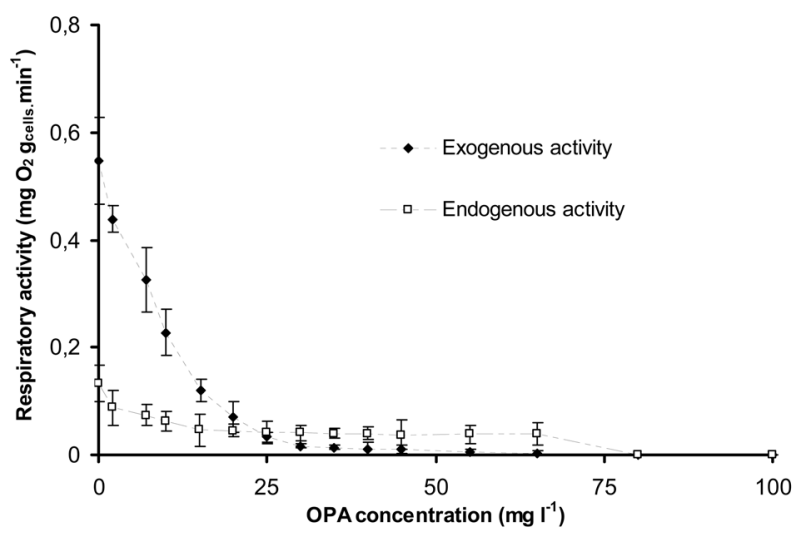

Figure 1. Exogenous and endogenous respiratory activity of $P$. fluorescens as a function of OPA concentration. 
cells per $\mathrm{ml}$ of bacterial suspension and the number of colony formation units (CFU) $\mathrm{ml}^{-1}$ of bacterial suspension, as a function of OPA concentration.

The activity of the biocide (OPA) on the respiratory activity of $P$. fluorescens, evaluated by the measurement of the oxygen uptake rate due to glucose oxidation, gives the fraction of the cells that are active, since they exhibit metabolic activity (see Figure 1). The use of respiratory activity showed that when bacterial cells were exposed to OPA concentrations $>80 \mathrm{mg} \mathrm{l}^{-1}$ bacterial activity was not detected when measured as the exogenous respiration rate $\left(\mathrm{MBC}=80 \mathrm{mg} 1^{-1}\right)$. For OPA concentrations between 20 and $80 \mathrm{mg} \mathrm{l}^{-1}$, a substantial decrease in exogenous respiratory activity was observed. For low OPA concentrations $\left(<20 \mathrm{mg} \mathrm{l}^{-1}\right)$, the decrease in activity was very sharp and dependent on OPA concentration. Comparison of both rates showed that exogenous respiration rate was more dependent on biocide concentration than on endogenous respiration rate. However, P. fluorescens retained considerable endogenous activity that remained more or less constant for a large range of OPA concentrations. Furthermore, the endogenous activity for OPA concentrations $>20 \mathrm{mg} \mathrm{l}^{-1}$ was even higher than the exogenous activity.

Figure 2 shows the number of $P$. fluorescens cells after OPA contact for $30 \mathrm{~min}$ exhibiting different colours due to BacLight viability staining. The colour differences between viable (green) and nonviable (red) bacteria were very easy to distinguish (see Figure 3). However, for the intermediate range of
OPA concentrations (between $2 \mathrm{mg} \mathrm{l}^{-1}$ and $65 \mathrm{mg}^{-1}$ ) some green cells appeared yellowish and some red cells appeared orange, depending on biocide concentration. For $80 \mathrm{mg}^{-1}$ and for $100 \mathrm{mg}^{-1}$ of OPA only red and green red cells could be found. The MBC determined using this method was $100 \mathrm{mg}^{-1}$ and for a concentration of $80 \mathrm{mg}^{-1}$ of OPA, the $\log$ reduction was 1.8 .

Figure 4 displays the number of bacterial viable cells calculated according to different approaches: (i) Boulos et al. (1999) consider cells fluorescing green and yellow as viable and cells fluorescing red and orange as nonviable; (ii) the manufacturer of the BacLight kit considers green cells as viable and red, yellow and orange cells as nonviable. As expected, for both approaches, viable counts decreased with the increase in biocide concentration. However, in the above mentioned intermediate range of concentrations (between $2 \mathrm{mg} \mathrm{l}^{-1}$ and $65 \mathrm{mg} \mathrm{l}^{-1}$ ), some differences between the results obtained by each approach are noticeable.

Figure 5 presents the total bacterial counts in terms of CFU as function of OPA concentration. It should be noticed that even before treatment with OPA, the number of CFU was not comparable with the number of bacteria counted by direct microscopy, since the BacLight viable counts were always much higher than the plate count numbers, with a difference of about $1 \mathrm{log}$. The results obtained using the culture method showed that the MBC is $65 \mathrm{mg} \mathrm{l}^{-1}$.

For OPA concentration of $7 \mathrm{mg}^{-1}$, the decrease of bacterial culturability corresponded to a $\log$

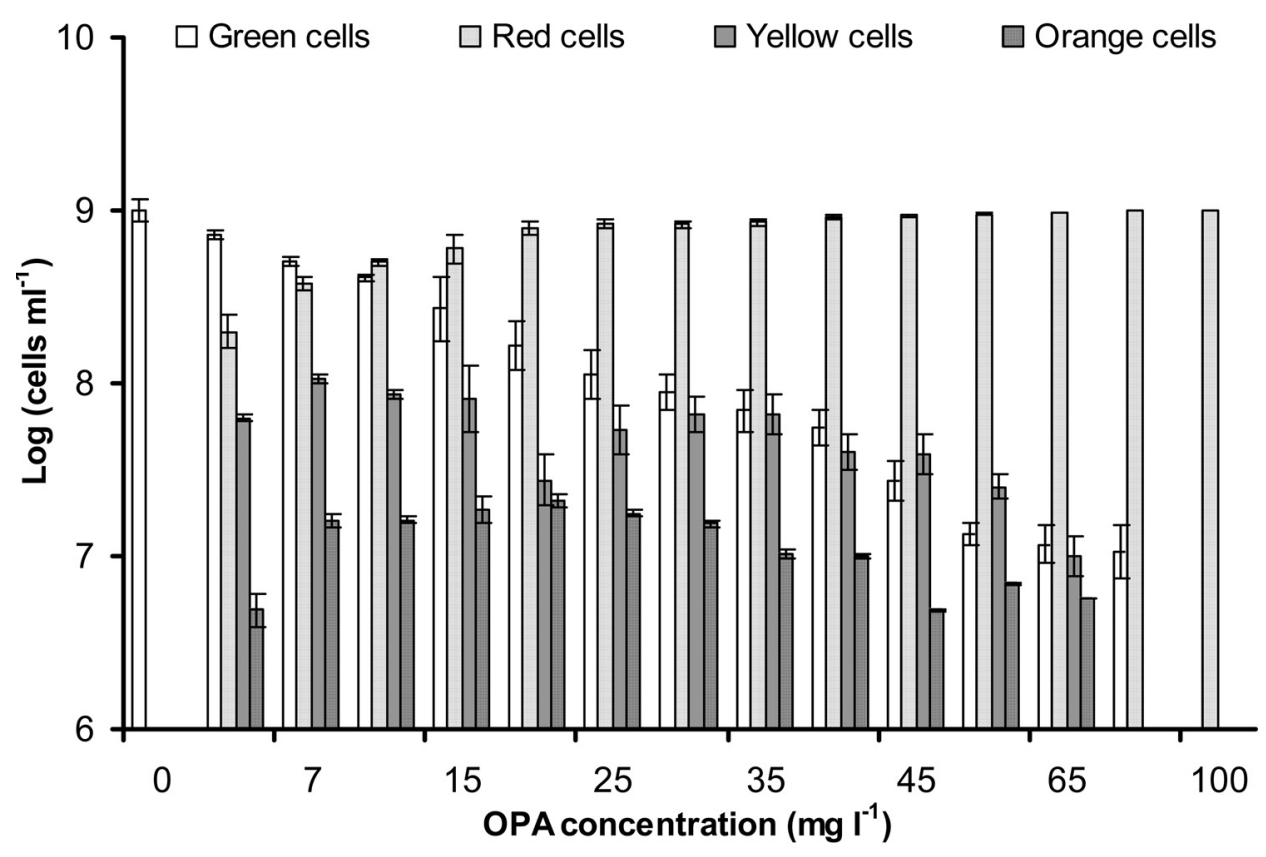

Figure 2. Effect of different OPA concentrations on P. fluorescens cells, examined by BacLight stains. 

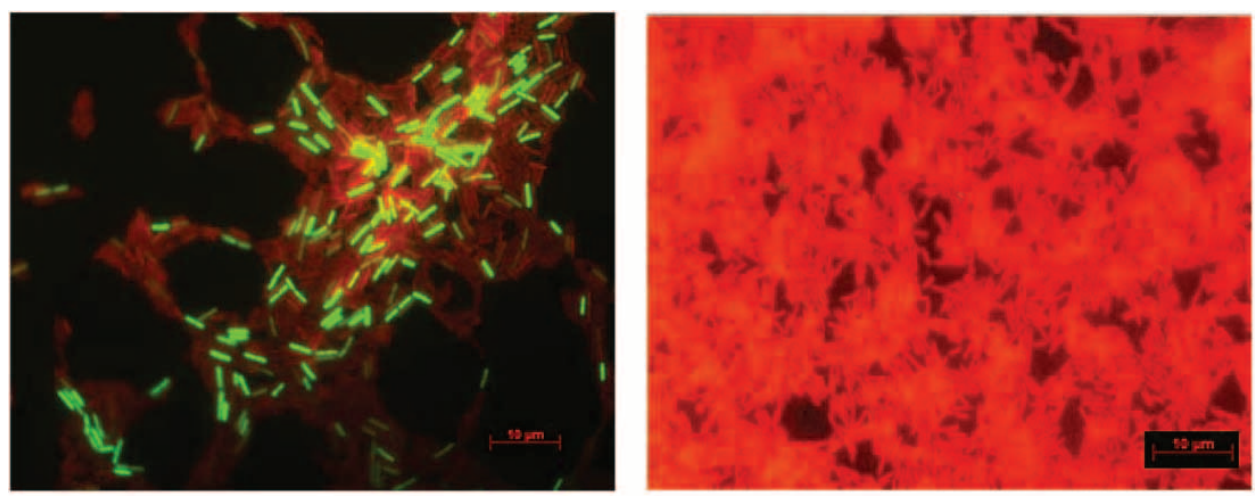

A

B

Figure 3. Epifluorescence photomicrograph of planktonic cells of $P$. fluorescens after application of 55 (A) and $100 \mathrm{mg} 1^{-1}$ of $\mathrm{OPA}(\mathrm{B}) . \mathrm{A}=\mathrm{x}$ 1320; $\mathrm{B}=\mathrm{x} 1000$; scale $\mathrm{bar}=10 \mathrm{um}$.

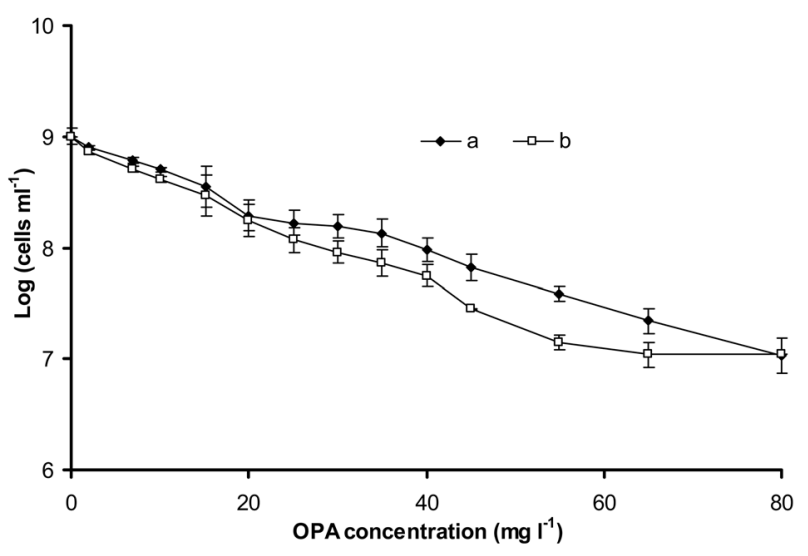

Figure 4. Number of viable cells obtained by the Live/Dead ${ }^{\circledR}$ BacLight ${ }^{\mathrm{TM}}$ Bacterial Viability kit, as a function of OPA concentration. a) = according to Boulos et al. (1999); b) = according to the BacLight kit manufacturer.

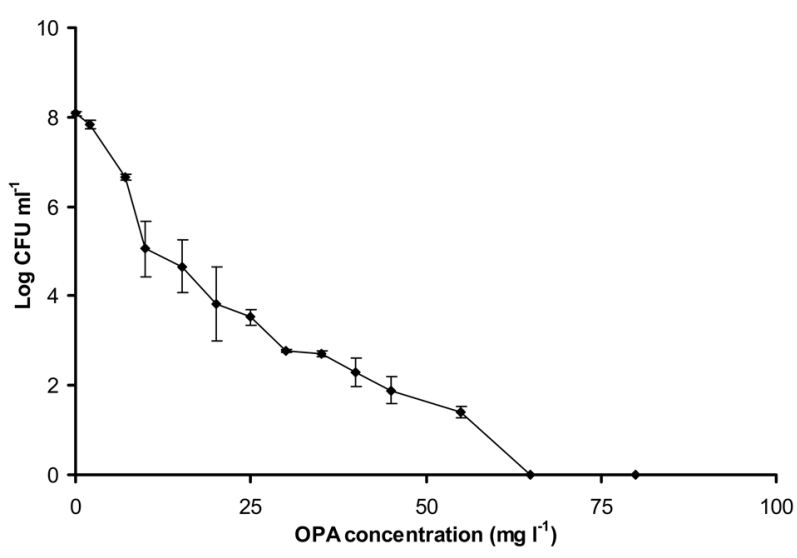

Figure 5. Total bacterial counts (colony forming units-CFU), as a function of OPA concentration.

reduction of 1.4. However, a $5 \log$ reduction in the number of $\mathrm{CFU}$ was registered for concentrations $>25 \mathrm{mg}^{-1}$.
For comparative purposes, the loss of bacterial activity, viability and culturability were calculated and are presented in Figure 6, which clearly shows that bacteria lose culturability and yet still exhibit clear signs of metabolic activity and viability.

Indeed, OPA induced a sharp decrease in culturability (CFU counts) that was more pronounced than the loss of bacterial activity and viability. For small OPA concentrations, cells lost culturability abruptly while maintaining activity and viability. It can be seen that the BacLight viable counts, calculated using the above approaches, decreased much less than did the loss of activity monitored by respiratory activity. A loss of bacterial viability of about $90 \%$ was obtained for a concentration of $40 \mathrm{mg}^{-1}$ of biocide (BacLight kit) while a $90 \%$ loss of activity was assessed for $20 \mathrm{mg}^{-1}$ of OPA, i.e. the MBC to obtain a reduction of $90 \%$ is $40 \mathrm{mg}^{-1}$ or $20 \mathrm{mg}^{-1}$ using the viability and activity assessments respectively. The overall results presented in Figure 6 show that a large number of bacterial cells retained physiological and metabolic activity after biocide treatment, while most of them could not form colonies on conventional medium.

Using the data depicted in Figure 6, some correlations were made in order to evaluate the possibility of obtaining linear relationships between the various test methods. Those correlations showed that the loss of activity assessed by respiratory activity and the loss of viability by BacLight staining, counting yellow cells as viable, had a good correlation factor $\left(R^{2}=0.974\right)$. Nevertheless, the results of the latter methods were not statistically equivalent $(p<0.001)$, suggesting the existence of significant differences in the efficacy of the biocide through assessment of bacterial viability using BacLight viability kit and the respiratory activity method. Conversely, if the yellow cells were enumerated as 


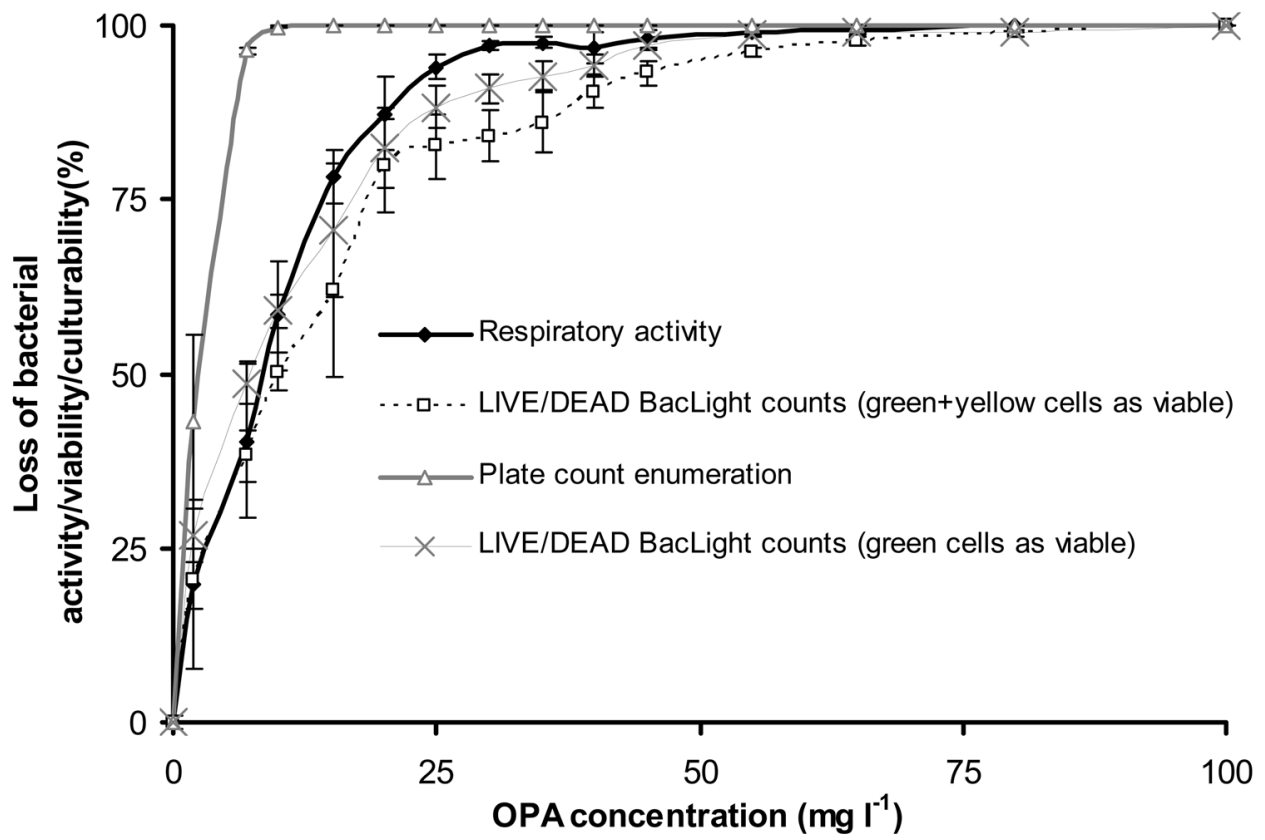

Figure 6. Loss of bacterial activity, viability and culturability assessed by respirometric activity (oxygen uptake rate - exogenous activity), the Live/Dead ${ }^{\mathbb{R}}$ BacLight ${ }^{\mathrm{TM}}$ bacterial viability kit and colony forming ability.

nonviable, these methods were strongly correlated, with a $\mathrm{R}^{2}=0.982$, and were not statistically different $(p>0.10)$.

The results obtained by BacLight counts, considering yellow cells as viable, and by the plate count method had a poor correlation factor of 0.433 $(p<0.01)$. Counting yellow cells as nonviable, the correlation factor $\mathrm{R}^{2}$ increased to 0.637 but the methods were still statistically different $p<0.01$. The linear adjustment of the loss of activity and the plate count results are correlated with a factor of $0.549(p<0.02)$.

\section{Discussion}

As stated by Stewart et al. (1994), specific methods based on the physiological or metabolic activity supply more information on the action of the products used as biocides than the ability to grow and form colonies on a solid media. Later, McFeters et al. (1995) also showed that the determination of the oxygen uptake levels is more accurate than the traditional methods of bacterial enumeration by colony formation on agar media. These plate count method may overestimate biocide efficacy since bacteria may remain viable after biocide application but may not grow on solid media. This loss of culturability led to the assumption that bacterial cells in this state were viable but not culturable (VBNC) cells (McDougald et al. 1998; Kawai et al. 1999).

Respiratory activity was affected by the action of the biocide (see Figure 1) but no activity was observed at very high biocide concentrations. Similar decreases in both endogenous and exogenous respiration rates were expected. However, endogenous metabolism was affected to a lesser extent than exogenous. These results suggest that even if the cells are not able to oxidize external substrates after contact with the biocide they may recover when the biocide is removed, since they maintain basal metabolism even in the presence of high biocide concentrations. The endogenous metabolism should be seen as a state where no net growth is observed. When bacterial cells are depleted of external substrates or faced with factors that cause stress, the cells often use intracellular materials as an energy source to maintain their survival (Russell \& Cook, 1995). Several authors (Gilbert et al. 1990; McDougald et al. 1998) reported a similar effect to that found in this study, where bacteria can become exogenously dormant in response to unfavourable environmental conditions whilst still maintaining residual metabolism.

The different range of colours found after biocide application and L/D BacLight visualization (see Figures 2 and 3 ) is attributed to the different metabolic states of the bacteria. Maukonen et al. (2000) studying the food borne bacteria L. monocytogenes and $P$. fragi, also reported the appearance of yellow and orange cells after staining with the BacLight kit. They considered those cells injured, meaning that they could probably recover and reproduce after a period of time. Based on this argument, in the present work, the appearance of 
injured cells (Figure 2) was dependent on the OPA concentration, since an increase in the concentration lower than the lethal concentration $\left(100 \mathrm{mg} \mathrm{l}^{-1}\right)$ gave rise to the appearance of a greater number of yellow and orange cells, while for the higher OPA concentrations (higher than the lethal concentration) only red cells were found.

The difference in the loss of viability assessed by BacLight stains and respiratory activity (see Figure 6) may be due to the number of injured cells. Some of the bacteria that had no respiratory activity but fluoresced green and yellow, were probably in a stressed state, justifying the different MBC given by each method. Indeed, even though some authors (Defives et al. 1999; Ericsson et al. 2000) advocate that the BacLight viability kit avoids discrepancies in counts of total and viable bacteria, the methodology cannot discriminate the cellular status of the cells. The state of some of the total viable cells, detected by the BacLight stains, could be seen as a transitory stage in the degeneration of the bacterial cells. However, it is not possible to quantify whether the SYTO 9 dye could give false viable cells (Lehtinen et al. 2004; Stocks, 2004) since the exogenous respiration results suggested that these cells may be dead. Braux et al. (1999) also reported a discrepancy effect in the results of oxidative stress caused by periacetic acid measured by respirometry using CTC, BacLight viable counts and plate counts, respectively. No significant effect was observed with BacLight viable counts, compared to the other methods. Their results suggested that respiratory activity and culturability are more rigorous criteria to assess the effect of chemical stress than membrane permeability assessed by PI uptake. Furthermore, the use of fluorescent dyes may have some drawbacks. Dyes may be toxic to the bacteria at concentrations used in the assays and some viable bacteria may not incorporate the dye or may accumulate insufficient dye to become detectable (Hatzinger et al. 2003). Moreover, after the application of fluorescent dyes the bacterial cells cannot be used in further studies. Conversely, with the respirometry based on oxygen uptake, subsequent analysis such as the re-establishment of respiration after biocide removal or inactivation (re-growth) can be carried out.

The number of viable cells (Figure 4) and culturable cells (Figure 5) before biocide treatment were not comparable (difference of about $1 \mathrm{log}$ ), which is probably related to the limitations of the plate count method. It has long been recognized that the single use of culture-based enumeration techniques may significantly underestimate the numbers of viable cells. Several reasons may account for this difference: (i) the presence of starved or injured cells or potentially viable but nonculturable cells (VBNC) (Banning et al. 2002) that are not able to initiate cell division at a sufficient rate to form colonies; (ii) inadequate culture conditions; (iii) aggregation of bacteria that can lead to the formation of one colony from more than one cell, thereby underestimating the total number of cells. Ericsson et al. (2000) also considered that the method of cultivation on a solid medium is often inadequate due to the failure of the bacterial cell to reproduce on standard nutrient agar plates. Nevertheless, this may not mean that the cells were nonviable. Cells can be viable but lack the ability to divide. It can also be argued that the viability method based on Baclight can overestimate the number of viable cells as appeared to be suggested by the activity results. Ericsson et al. (2000) showed that even cells that fluoresced green after staining with BacLight, had different reproductive responses; cells could divide more than once, divide only once or not show the ability to divide in a counting chamber. Those cells probably lost their potential to form colonies, but they remain physically intact and metabolic active or with a diminished activity. These arguments are reinforced by the discrepancy encountered between the activity and the viability results.

The inconsistency between the number of culturable and viable cells increases with the application of biocide. After biocide application, the comparison of Figures 2 and 3 with Figure 5 show that, for the same OPA concentration, higher numbers of viable bacteria are detected by the BacLight kit than the culturable bacteria found on the PCA plates. This comparison indicates the probable existence of VBNC bacteria. The limitations of the plate count method can also be observed, for instance, for a biocide concentration of $55 \mathrm{mg}^{-1}$, where BacLight viable counts exceeded the number of $\mathrm{CFU}$ by at least 5 orders of magnitude (Figure 6). Consequently, the poor correlation factors calculated between the loss data obtained using culturability and viability, as well as the lack of statistical significance. So, the number of CFU is an underestimate of the actual viable population, since the bacteria exhibit activity and are viable after biocide application but are not able to grow on solid media as also reported by McDougald et al. (1998).

The results obtained with cells in suspension suggest that the Live/Dead kit gives the most conservative estimate of biocidal efficacy and may be the most useful method. Besides being a method that gives a higher MBC, it is expensive and time consuming. Furthermore, application of the BacLight viability kit to determine the biocidal efficacy of OPA against biofilms (Simões et al. 2003a) proved to be inaccurate due cell aggregation promoted by extracellular polymeric substances (EPS) and to the reaction of the dyes with the EPS, as shown in Figure 7. 


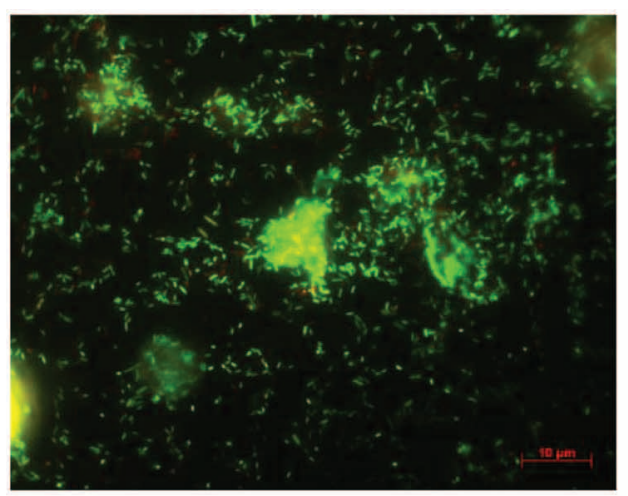

A

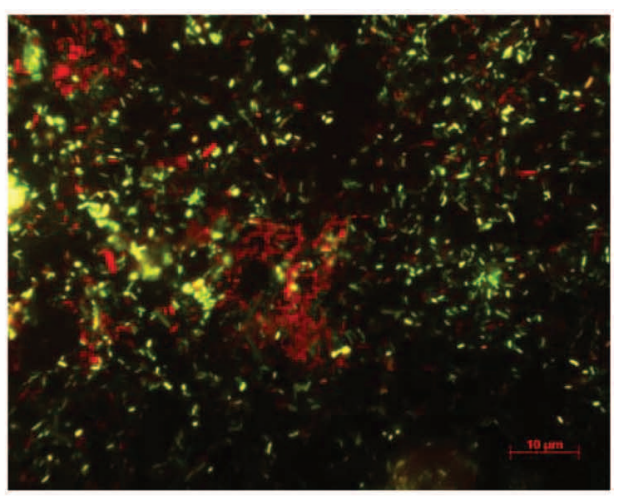

B

Figure 7. Epifluorescence photomicrograph of cells within biofilms formed by P. fluorescens before OPA treatment (A) and after application of $50 \mathrm{mg}^{-1}$ of OPA (B). x 1000; bar $=10 \mu \mathrm{m}$.

The respiratory activity of $P$. fluorescens biofilms on stainless steel surfaces after treatment with biocides, including OPA, has been reported previously (Simões et al. 2003b; 2003c). These assays were performed on biofilms immediately after exposure to the biocides and showed the high potential of the respiratory technique to assess efficacy against intact biofilms.

\section{Conclusions}

The use of different methods to evaluate biocide efficacy can lead to different conclusions regarding the effects caused by the biocide. Different MBC values were obtained depending on the method used to assess the efficacy of the biocide: $80 \mathrm{mg}^{-1}$ by respiratory method, $100 \mathrm{mg}^{-1}$ by the viability and $65 \mathrm{mg}^{-1}$ by the culturability method. Short-term respirometry is a rapid, reliable, economic and easy methodology that can be used to evaluate biocide efficacy against aerobic, heterotrophic, carbonconsuming bacteria.

\section{Acknowledgements}

The authors acknowledge the financial support provided by IBQF and FCT, and the Portuguese Foundation for Science and Technology, through the project POCTI/1999/BIO/35683 and $\mathrm{PhD}$ grant awarded to Manuel Simões.

\section{References}

APHA, AWWA, WPCF. 1989. Standard methods for the examination of water and wastewater. 17th edition, Clesceri LS, Greenberg AE, Trussel RR, editors. American Public Health Association, Washington DC, USA.

Banning N, Toze S, Mee B J. 2002. Escherichia coli survival in groundwater and effluent measured using a combination of propidium iodide and the green fluorescent protein. J Appl Microbiol 93: 9-76.
Boulos L, Prévost M, Barbeau B, Coallier J, Desjardins R. 1999. Live/Dead ${ }^{\mathrm{E}}$ Bac Light $^{\mathrm{TM}}$ : application of a new rapid staining method for direct enumeration of viable and total bacteria in drinking water. J Microbiol Methods 37: 77-86.

Braux A S, Minet J, Tamanai-Shacoori Z, Riou G, Cormier M. 1999. Direct enumeration of injured Escherichia coli cells harvested onto membrane filters. J Microbiol Methods 31: 18.

Defives C, Guyard S, Oularé M M, Mary P, Hornez J P. 1999. Total counts, culturable and viable, and non-culturable microflora of a French mineral water: a case study. J Appl Microbiol 86: 1033-1038.

Ericsson M, Hanstorp D, Hagberg P, Enger J, Nyström T. 2000. Sorting out bacterial viability with optical tweezers. J Bacteriol 182: $5551-5555$.

Gilbert P, Collier P J, Brown M R W. 1990. Influence of growth rate on susceptibility to antimicrobial agents biofilms, cell cycle, dormancy, and stringent response. Antimicrob Agents Chemother 34: $1865-1868$.

Hatzinger P B, Palmer P, Smith R L, Peñarrieta C T, Yoshinari T. 2003. Application of tetrazolium salts for the measurement of respiratory activity and viability of groundwater bacteria. J Microbiol Methods 52: 47- 58.

Johnson S A, Goddard P A, Liffe C, Timmins B, Rickard A H, Robson G, Handley P S. 2002. Comparative susceptibility of resident and transient hand bacteria to para-chlorometa-xylenol and triclosan. J Appl Microbiol 93: 336344.

Kawai M, Yamaguchi N, Nasu M. 1999. Rapid enumeration of physiologically active bacteria in purified water used in the pharmaceutical manufacturing process. J Appl Microbiol 86: $496-504$.

Lehtinen J, Nuutila J, Lilius E-M. 2004. Green fluorescent protein-propidium iodide (GFP-PI) based assay for flow cytometric measurement of bacterial viability. Cytometry Part A 60A: $165-172$.

Maukonen J, Mattila-Sandholn T, Wirtanen G. 2000. Metabolic indicators for assessing bacterial viability sampling using cells in suspension and swabbed biofilm. Libensmittel-Wiss Technol 33: $225-233$.

McDougald D, Rice S A, Weichart D, Kjelleberg S. 1998. Nonculturability: adaptation or debilitation? FEMS Microbiol Ecol 25: 1-9.

McFeters G A, Yu F P, Pyle B H, Stewart P S. 1995. Physiological methods to study biofilm disinfection. J Ind Microbiol 15: $333-338$. 
Molecular Probes Live/Dead BacLight ${ }^{\mathrm{TM}}$ bacteria viability kit technical sheet. Molecular Probes Inc., 1998.

Oliveira R, Melo L, Oliveira A, Salgueiro R. 1994. Polysaccharide production and biofilm formation by Pseudomonas fluorescens: effects of $\mathrm{pH}$ and surface material. Colloids Surf B, Biointerfaces 2: $41-46$.

Pereira M O, Vieira M J. 2001. Effects of the interactions between glutaraldehyde and the polymeric matrix on the efficacy of the biocide against Pseudomonas fluorescens biofilms. Biofouling 17: 93- 101 .

Russell J B, Cook G M. 1995. Energetics of bacterial growth: Balance of anabolic and catabolic reactions. Microbiol Rev 59: $48-62$.

Simões M, Pereira M O, Vieira M J. 2003a. Monitoring the effects of biocide treatment of Pseudomonas fluorescens formed under different flow regimes. Water Sci Technol 47: $217-$ 223.

Simões M, Carvalho H, Pereira M O, Vieira M J. 2003b. Effect of different concentrations of ortho-phthalaldehyde on biofilms formed by Pseudomonas fluorescens under different flow conditions. Biofouling 19: 287-295.

Simões M, Carvalho H, Pereira M O, Vieira M J. 2003c. Studies on the behaviour of Pseudomonas fluorescens biofilms after orthophthalaldehyde treatment. Biofouling 19: 151-157.

Simões M, Pereira M O, Vieira M J. 2005. Action of a cationic surfactant on the activity and removal of bacterial biofilms formed under different flow regimes. Water Res 39: $478-$ 486.
Smith J J, McFeters G A. 1997. Mechanisms of INT (2-(4iodophenyl)-5-phenyl tetrazolium chloride), and CTC (5cyano-2, 3-ditolyl tetrazolium chloride) reduction in Escherichia coli K-12. J Microbiol Methods 29: 161-175.

Stewart P S, Griebe T, Srinivasan R, Chen C-I, Yu F P, deBeer D, McFeters G A. 1994. Comparation of respiratory activity and culturability during monochloramine disinfection of binary population of biofilms. Appl Environ Microbiol 60: 16901692.

Stocks S M. 2004. Mechanism and use of the commercially available viability stain BacLight. Cytometry Part A 61A: $189-$ 195.

Terzieva S, Donnelly J, Ulevicius V, Grinshpun S A, Willeke K, Stelma G N, Brenner P N. 1996. Comparison of methods for detection and enumeration of airborne micro-organisms collected by liquid impingement. Appl Environ Microbiol 62: $2264-2272$.

Virta M, Lineri S, Kankaanpää P, Karp M, Peltonen K, Nuutila J, Lilius E-M. 1998. Determination of complement-mediated killing of bacteria by viability staining and bioluminescence. Appl Environ Microbiol 64: 515-519.

Walsh S E, Maillard J-Y, Russell A D. 1999. Ortho-phthalaldeheyde: a possible alternative to glutaraldehyde for high level disinfection. J Appl Microbiol 86: 1039 - 1046.

Yoshinori H, Kazuhide K. 2002. Rapid assessment of the physiological status of the polychlorinated biphenyl degrader Comamonas testosteroni TK102 by flow cytometry. Appl Environ Microbiol 68: $2031-2035$. 